\title{
APLICAÇÃO DA METODOLOGIA DAS 8 DISCIPLINAS PARA REDUÇÃO DE UMA NÃO CONFORMIDADE EM UMA EMPRESA DO SETOR AUTOMOTIVO
}

\author{
APPLICATION OF THE 8 DISCIPLINES METHODOLOGY TO REDUCE A NON-CONFORMITY IN \\ A COMPANY IN THE AUTOMOTIVE SECTOR
}

\author{
Lucas Pavani Soligo ${ }^{1} \&$ Deivid Marques Nunes ${ }^{2}$ \\ 12 Universidade Federal de Catalão - UFCAT \\ ${ }^{1}$ lucassoligo97@gmail.com ${ }^{2 *}$ nunesdm@ufg.br
}

\section{ARTIGO INFO.}

\section{Recebido em: 19.11.2021}

Aprovado em: 20.12.2021

Disponibilizado em: 22.12.2021

\section{Palavras-Chave:}

Ferramentas da qualidade. Metodologia 8D. Setor automotivo.

\section{KEYWORDS:}

Quality tools. 8D Methodology. Automotive sector.

*Autor Correspondente: Nunes, D. M.

\section{RESUMO}

Este trabalho tem como objetivo apresentar a aplicação da metodologia estruturada das 8 disciplinas (8D) para resolução de problemas em uma fábrica do ramo automobilístico. Esta não conformidade foi analisada utilizando diversas ferramentas e seguindo as etapas da metodologia $8 \mathrm{D}$, o problema em questão foi detectado na operação de desempeno de eixos de transmissões, devido um grande aumento no índice de trincas durante os meses de dezembro de 2020 e janeiro de 2021. Para a elaboração deste artigo foi feito um estudo de caso, onde todos os dados utilizados foram coletados durante os meses de dezembro de 2020 até agosto de 2021. Após concluir as 8 etapas da metodologia, com todas as análises feitas e ações implementadas, foi encontrada uma ação corretiva eficiente e eficaz para a não conformidade, gerando uma redução de, aproximadamente, $96 \%$ no índice de trincas.

\begin{abstract}
This work aims to present the application of the structured methodology of the 8 disciplines (8D) for problem solving in a factory in the automobile industry. This non-conformity was analyzed using several tools and following the steps of the $8 D$ methodology, the problem in question was detected in the transmission shaft straightening operation, due to a large increase in the crack index during the months of December 2020 and January 2021. For the preparation of this article, a case study was carried out, where all the data used were collected during the months of December 2020 until August 2021. After completing the 8 steps of the methodology, with all the analyzes carried out and actions implemented, it was found an efficient and effective corrective action for non-compliance, generating a reduction of approximately $96 \%$ in the crack rate.
\end{abstract}




\section{INTRODUÇÃO}

O setor automotivo teve uma significativa crescente nos últimos tempos, batendo em 2018, o maior crescimento dos últimos 11 anos, na casa dos 15,1\% (Veja, 2019), tal fato deveu-se a reduções de impostos e lançamentos de novos carros por parte das montadoras. Mesmo assim, no início do ano de 2019, a associação que representa o setor, estimulou outro crescimento de 11,4\% nas vendas em relação ao ano interior (Folha de São Paulo, 2019).

No início do ano de 2020, por conta da pandemia recorrente no mundo todo e a grande crise mundial vivida até hoje, as produções e vendas do setor automotivo foram gravemente afetadas (Folha de São Paulo, 2020). E consequentemente, as empresas que forneciam componentes para as montadoras, também tiveram seu faturamento impactado.

Com esse cenário de crise, passou a ser, ainda mais, de suma importância que essas empresas cortassem alguns custos desnecessários da produção, mas que isso não afetasse na qualidade e eficiência daquele processo, aliando os custos operacionais à qualidade final do produto entregue, de maneira a se manter competitiva no mercado em que esta inserida. A produção enxuta é umas das metodologias mais adotadas em grandes empresas dos EUA, já que, além de aumentar a produtividade da empresa, consegue torna-la mais competividade em um mercado cada vez mais globalizado (Abdulmalek \& Rajgopal, 2006).

Segundo Montgomery (2017), inspecionar os produtos é uma ideia inviável. O processo deve ser estável e capaz de garantir que o produto seja feito corretamente da primeira vez, diminuindo a necessidade de se ter o conhecimento da variabilidade do processo. Contudo, mesmo com a extrema automação das cadeias produtivas no mundo atual, qualquer processo vai ter sua taxa de variabilidade, tornando indispensável a realização de estudos internos, e contínuos, nas organizações, com o intuito de identificar problemas presentes, analisá-los e através de metodologias estruturadas, resolvê-los.

Uma das metodologias estruturadas é a metodologia das 8 Disciplinas (8D) que auxilia na identificação, análise e resolução de problemas através do estudo de dados obtidos, utilizando ferramentas da qualidade, que ajudam na melhoria do processo e, consequentemente, do produto final.

Uma vez contextualizado o cenário em que se encontra o mundo atual e entendendo que as empresas precisam sempre buscar a melhoria em seus processos e produtos para se manterem competitivas, esse trabalho trata-se de um estudo de caso e tem como objetivo geral, apresentar uma aplicação do método 8D a fim de reduzir o índice de trincas em eixos, durante a operação de desempeno, em uma empresa do setor de componentes para transmissões.

\section{REFERENCIAL TEÓRICO}

\subsection{FERRAMENTAS DA QUALIDADE}

De acordo com Coutinho (2010), o maior objetivo da utilização de ferramentas da qualidade é conseguir comprovar e eliminar os problemas no menor espaço de tempo e com o menor gasto possível.

Segundo Vargas (2017) para evitar problemas e auxiliar no desenvolvimento de ações, as sete ferramentas da qualidade como diagramas de causa e efeito, diagrama de Pareto, histogramas, 
Citação (APA): Soligo, L. P. \& Nunes, D. M. (2021). Aplicação da metodologia das 8 disciplinas para redução de uma não conformidade em uma empresa do setor automotivo. Brazilian Journal of Production Engineering, 7(5), 312-324.

folha de verificação, diagrama de dispersão, gráfico de controle e fluxograma podem ser usadas separadamente ou até mesmo em conjunto para resolução de problemas presentes e gerar inúmeros benefícios (Figura 1).

Figura 1. As Sete Ferramentas da Qualidade

\begin{tabular}{|c|c|c|}
\hline FERRAMENTAS & O QUE É & PARA QUE UTILIZAR \\
\hline Folha de verificação & $\begin{array}{c}\text { Planilha para coleta de } \\
\text { dados }\end{array}$ & $\begin{array}{l}\text { Para facilitar a coleta de } \\
\text { dados }\end{array}$ \\
\hline Diagrama de Pareto & $\begin{array}{l}\text { Diagrama de barra que } \\
\text { ordena as ocorrências do } \\
\text { maior para o menor }\end{array}$ & $\begin{array}{c}\text { Priorizar os poucos e mais } \\
\text { vitais }\end{array}$ \\
\hline $\begin{array}{c}\text { Diagrama de causa e } \\
\text { efeito }\end{array}$ & $\begin{array}{c}\text { Estrutura do método que } \\
\text { expressa, de modo simples e } \\
\text { fácil, a série de causa de um } \\
\text { defeito } \\
\end{array}$ & $\begin{array}{l}\text { Ampliar a quantidade de } \\
\text { causas potenciais a serem } \\
\text { analisadas }\end{array}$ \\
\hline Diagrama de dispersão & $\begin{array}{c}\text { Giráfico cartesiano que } \\
\text { representa a relação entre } \\
\text { duas variáveis }\end{array}$ & $\begin{array}{c}\text { Verificar a correlação entre } \\
\text { duas variaveis }\end{array}$ \\
\hline Histograma & \begin{tabular}{|c|} 
Diagrama de barra que \\
represetnad a distribução da \\
ferramentas de uma \\
população \\
\end{tabular} & $\begin{array}{c}\text { Verificar o comportamento } \\
\text { de um processo em relaçao } \\
\text { a especificação }\end{array}$ \\
\hline Fluxograma & $\begin{array}{c}\text { São flunos que permite } \\
\text { vizualizar de forma global o } \\
\text { proceosse por onde passa o } \\
\text { produto } \\
\end{array}$ & $\begin{array}{l}\text { Estabelecer os limitese } \\
\text { conhecer as atividades }\end{array}$ \\
\hline Gráfico de controle & $\begin{array}{l}\text { Gráfico com limite de } \\
\text { controle que permite o } \\
\text { monitoramento dos } \\
\text { processos }\end{array}$ & $\begin{array}{l}\text { Verificar se o processo esta } \\
\text { sob controle }\end{array}$ \\
\hline
\end{tabular}

Fonte: Autores (2021)

\subsection{Métodos das melhorias de processo}

Ao longo dos anos tem-se observado uma grande necessidade, por parte das empresas, de sempre buscar melhorias tanto em seus produtos, como também em seus processos, aumentando sua produtividade e eficiência. Sendo assim, foram surgindo novas metodologias que viessem para ajudar as organizações nestas melhorias e na obtenção de um melhor controle de qualidade.

\subsubsection{Planejar-Fazer-Verificar-Ajustar (PDCA)}

Trata-se de uma técnica de gestão que consiste justamente nestes 4 passos e que possui o objetivo de melhorar os processos e os produtos de uma organização de continuamente. Segundo Paladini (2012), este ciclo foi proposto na década de 20 e tem como seu idealizador o engenheiro americano Walter Andrew Shewhart.

\subsubsection{Método de Análise e Soluções de Problemas (MASP)}

O MASP é um método de melhoria que apresenta 8 etapas para conseguir corrigir um problema, cada uma delas contribui para uma parte do estudo, desde a identificação do problema em 
questão, até a elaboração de ações corretivas para elimina-los. Para Almeida, Matias e Braga (2014) o MASP é uma atualização mais detalhada e subdividida do ciclo PDCA.

Segundo Martins (2016), esta metodologia é abordada nas empresas que aplicam a melhoria continua, a fim de evitar a análise superficial dos problemas, levando em consideração a relação entre as causas observadas e os efeitos delas sobre o processo. Solucionando problemas de maneira eficiente e eficaz.

\subsubsection{Método das 8 Disciplinas (8D)}

A metodologia 8D é uma ferramenta da qualidade que visa resolver problemas e melhorar processos e produtos por etapas. Segundo Vargas (2017), esse método representa uma sucessão de etapas bem organizadas, que caso bem executadas, geram uma solução para o problema em um curto espaço de tempo.

Para Cintra (2015), este método possui o objetivo de estudar o problema e encontrar as falhas existentes no processo, que causam as não conformidades. Além disso, tem o propósito de reduzir os custos de produção ao mesmo tempo que gera melhorias na qualidade do processo. Segundo Chies (2019), as etapas deste método podem ser apresentadas como:

- $\quad$ D1 - Definir equipe: Primeiramente, deve-se definir o líder do projeto e posteriormente escolher os demais membros. A equipe deve ser multifuncional, para que se tenha conhecimento técnico e gerencial, assim conseguindo ver de maneira mais ampla e generalizada aquele problema.

- $\quad$ D2 - Descrever o problema: Nesta etapa, deve-se identificar e especificar o problema em questão.

- $\quad$ D3 - Ação de contenção: Aqui, serão discutidas ações temporárias que estancaram aquele problema temporariamente e evite que o mesmo atinja o cliente enquanto ações definitivas sejam tomadas.

- $\quad$ D4 - Identificar causa raiz: Serão identificadas todas as possíveis causas para aquele problema. Em seguida, cada causa deve ser analisa para identificar a causa raiz da não conformidade.

- $\quad$ D5 - Identificar ação corretiva: Deve-se desenvolver ações corretivas permanentes sobre aquelas causas identificadas.

- $\quad$ D6 - Implementar ação corretiva: Nesta etapa, as ações desenvolvidas devem ser implementadas e métodos de acompanhamento devem ser elaborados para que o problema não volte a ocorrer.

- $\quad$ D7 - Prevenir ocorrências: Avaliar se aquelas ações tomadas foram realmente eficazes e se há a necessidade de alterações e melhorias nos procedimentos, instruções de controle, etc.

- $\quad$ D8 - Parabenizar a equipe: Reconhecimento do esforço do time, compartilhando as informações aprendidas e melhorias recorrentes ao estudo.

\section{METODOLOGIA}

Para realização deste estudo de caso, foi utilizado uma abordagem quantitativa com dados para analisar e desenvolver os pensamentos sobre a situação. Pode-se dizer que a natureza deste projeto é experimental, uma vez que se busca analisar as reações recorrentes de ações implementadas no processo em estudo. 
Este artigo foi realizado em uma planta do setor de transmissões de uma multinacional, localizada no interior do estado de São Paulo. Para a elaboração e desenvolvimento do projeto, foi escolhido um novo modelo de eixo em fabricação, pelo fato de ter apresentado um elevado índice de trincas nos últimos meses (Figura 2).

Figura 2. Mapeamento do processo de surgimento das trincas nos eixos de transmissão.

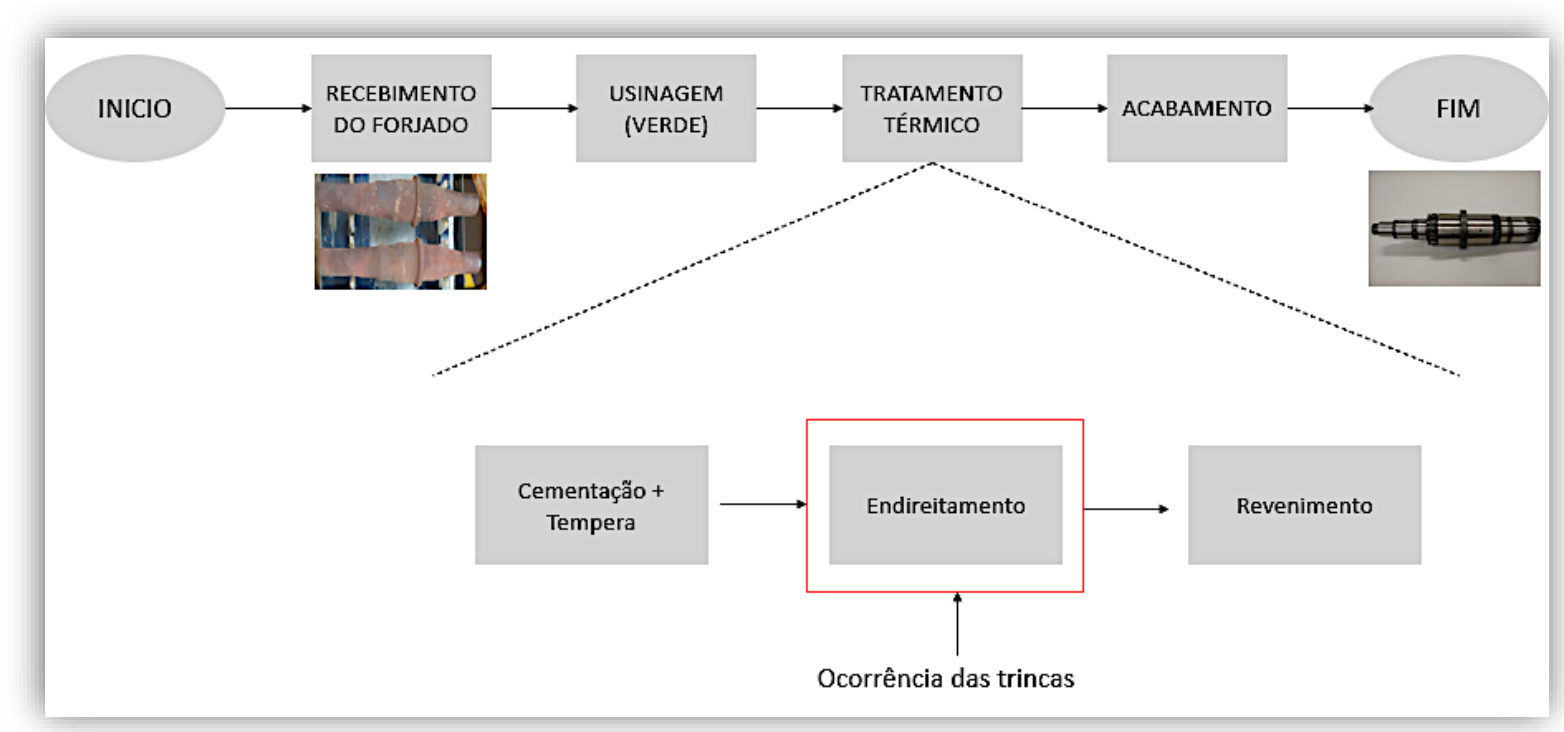

Fonte: Autores (2021)

As informações necessárias para conduzir este trabalho foram obtidas durante os últimos sete meses por meio de medições e observações diárias no processo em questão. Sendo assim, para organizar e estruturar os dados obtidos, analisa-los e buscar alcançar os objetivos, a metodologia das 8 disciplinas foi escolhida para dar andamento no projeto (Figura 3).

Figura 3. Fluxograma 8D

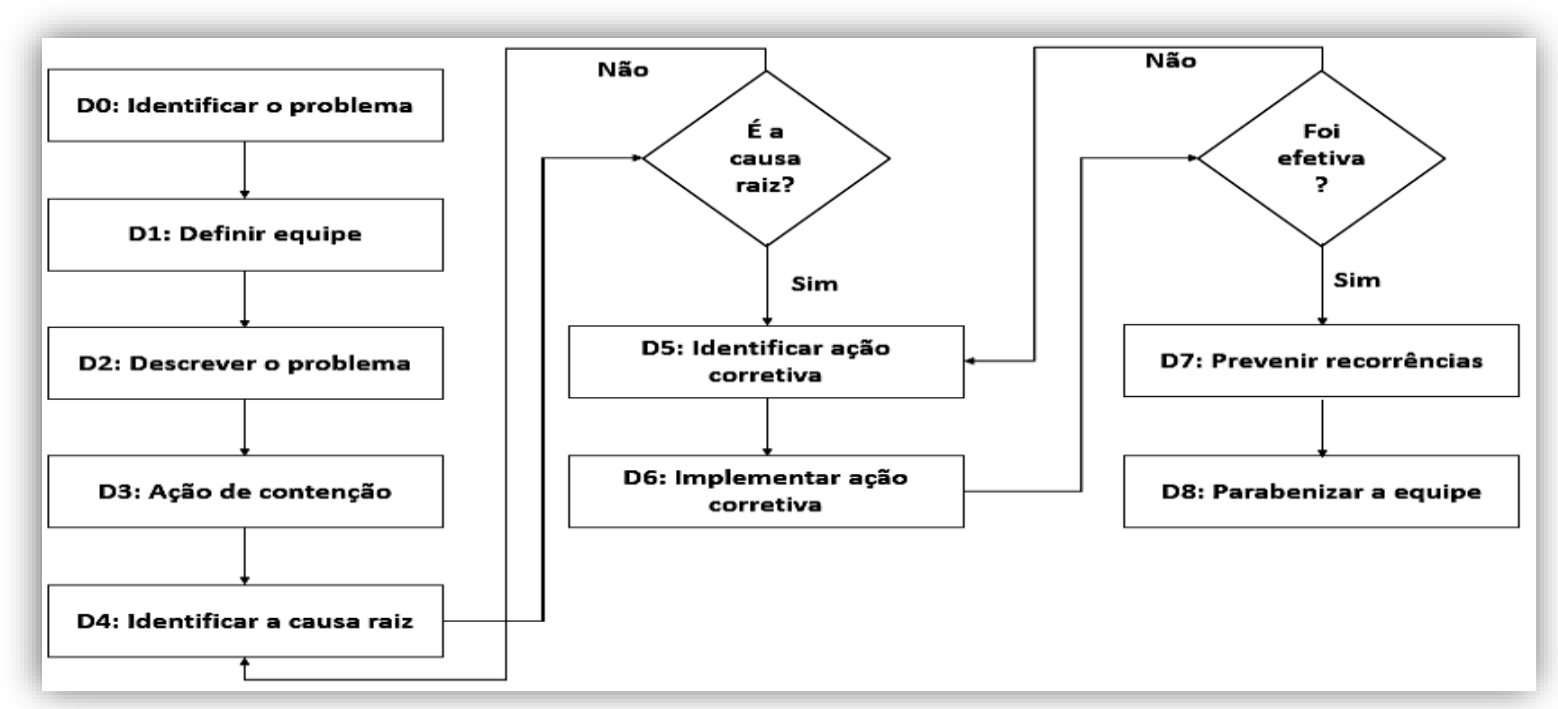

Fonte: Autores (2021)

Após a coleta e organização das informações, os dados foram tratados, com auxílio de softwares, com o intuito de facilitar por meio de gráficos, a visualização do tamanho e da gravidade do problema que seria enfrentado, comparando ao longo dos meses, a quantidade de

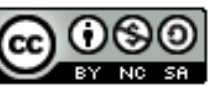


eixos desempenados pela quantidade de trincas ocorrentes. Em seguida, com a utilização de ferramentas da qualidade, foi elaborado uma ação temporária e corretiva para estancar o problema durante aquele momento. Com isso, ocorreram as etapas seguintes do método 8D, com o objetivo de elaborar uma ação corretiva eficiente e definitiva para que o problema não ocorra novamente.

\section{RESULTADOS}

\subsection{Identificações do problema}

O problema em estudo foi identificado na área de tratamento térmico, na operação de desempeno de eixos, conforme a Figura 4, que representa o percentual de trincas sobre o número total de eixos produzidos mensalmente.

Figura 4. Acompanhamento do índice de trincas

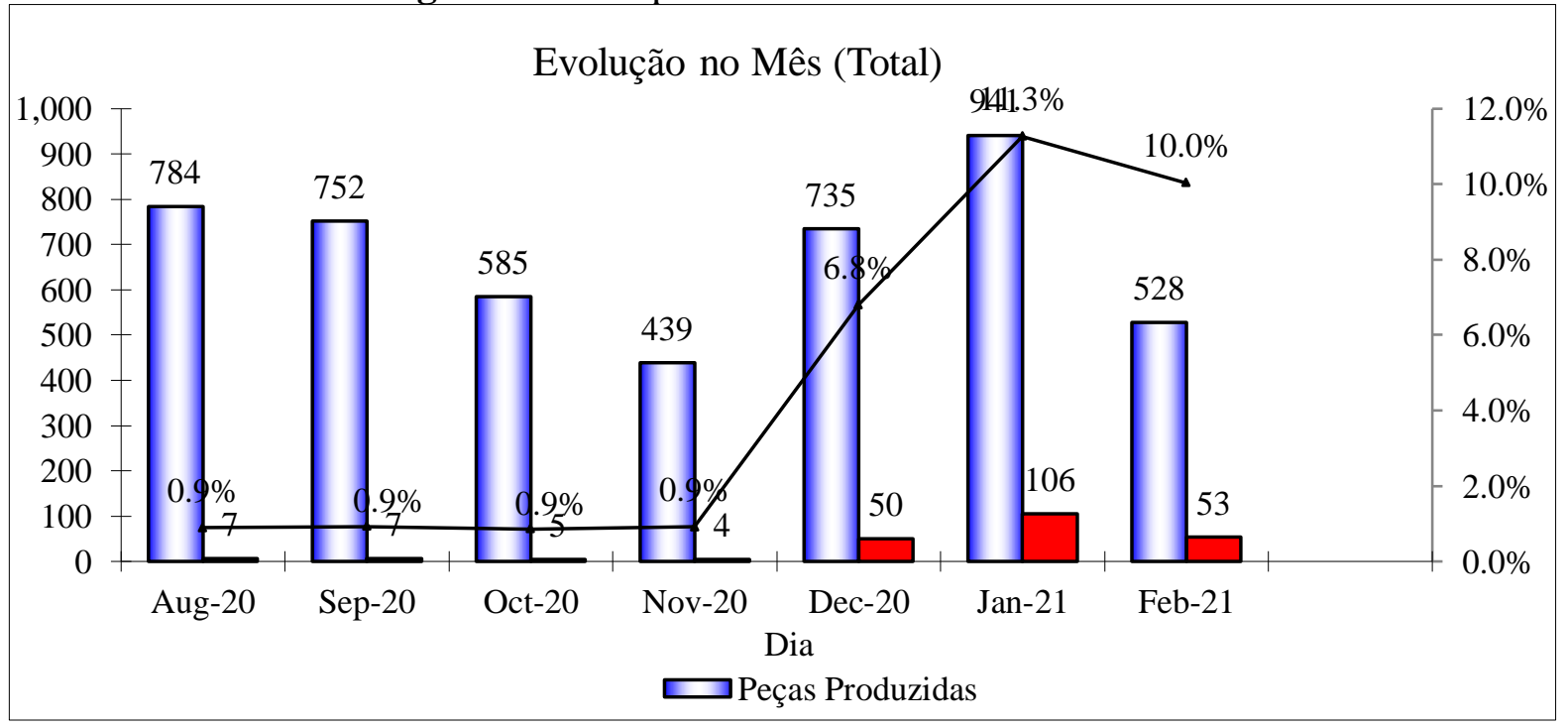

Fonte: Autores (2021)

Como observado na Figura 4, notou-se um consistente e baixo percentual de trincas durante o começo do $2^{\circ}$ semestre de 2020, porém, ao fim de dezembro é possível enxergar uma variação crescente em relação às não conformidades, com valores de $6,8 \%$ no mês de dezembro/2020, $11,3 \%$ no mês de janeiro/2021 e 10\% para o mês de fevereiro/2021. O valor máximo permitido para não-conformidades é de $1 \%$. Nesse período, essas não conformidades representaram para a organização uma perda considerável de $\mathrm{R} \$ 78.646,70$, o que se tornou necessária a tomadas de decisões para a minimização de itens não conformes.

\subsection{D1 - Definição da equipe}

A equipe de trabalho definida para realização do estudo foi multifuncional, liderada pelo engenheiro de manufatura responsável pela área de tratamento térmico e composta pelo técnico responsável pelo processo de desempeno, um técnico de qualidade, uma analista de qualidade e um estagiário em engenharia do tratamento térmico.

\subsection{D2 - Descrição do problema}

O problema em estudo está diretamente relacionado as imperfeições e curvaturas que podem surgir nos eixos após a realização do tratamento térmico, sendo necessário o seu desempeno 
pela máquina de endireitamento aplicando uma pressão pneumática em pontos estratégicos para a correção do grau de curvatura dos eixos.

A força aplicada é proporcional ao grau de desempeno, ou seja, quanto maior o ângulo de curvatura maior será força de compressão aplicada para correção, o que pode ocasionar as trincas.

\subsection{D3- Ação de contenção}

Nessa disciplina desenvolveram-se ações de contenção para o surgimento de trincas nos eixos de transmissão. Para isso, foi realizado um brainstorming com a equipe multifuncional e foi proposto aumentar a tolerância de liberação dos eixos na máquina de desempeno, nas estrias 32 $\mathrm{W}$ e $322 \mathrm{~W}$ de $120 \mu \mathrm{m}$ para $150 \mu \mathrm{m}$.

A tolerância de projeto máxima permitida era de $225 \mu \mathrm{m}$. Todas as etapas do processo sucessoras foram consultadas e aprovaram a alteração da tolerância de projeto, pois não impactaria no produto final.

Na Figura 5, foi possível verificar a redução do número de trincas, referente ao mês de abril/2021 para 1,5\%. A ação de contenção apresentou redução nos índices, porém não se atingiu a meta de $1 \%$ aceitável.

Figura 5. Índice de trincas no mês de abril

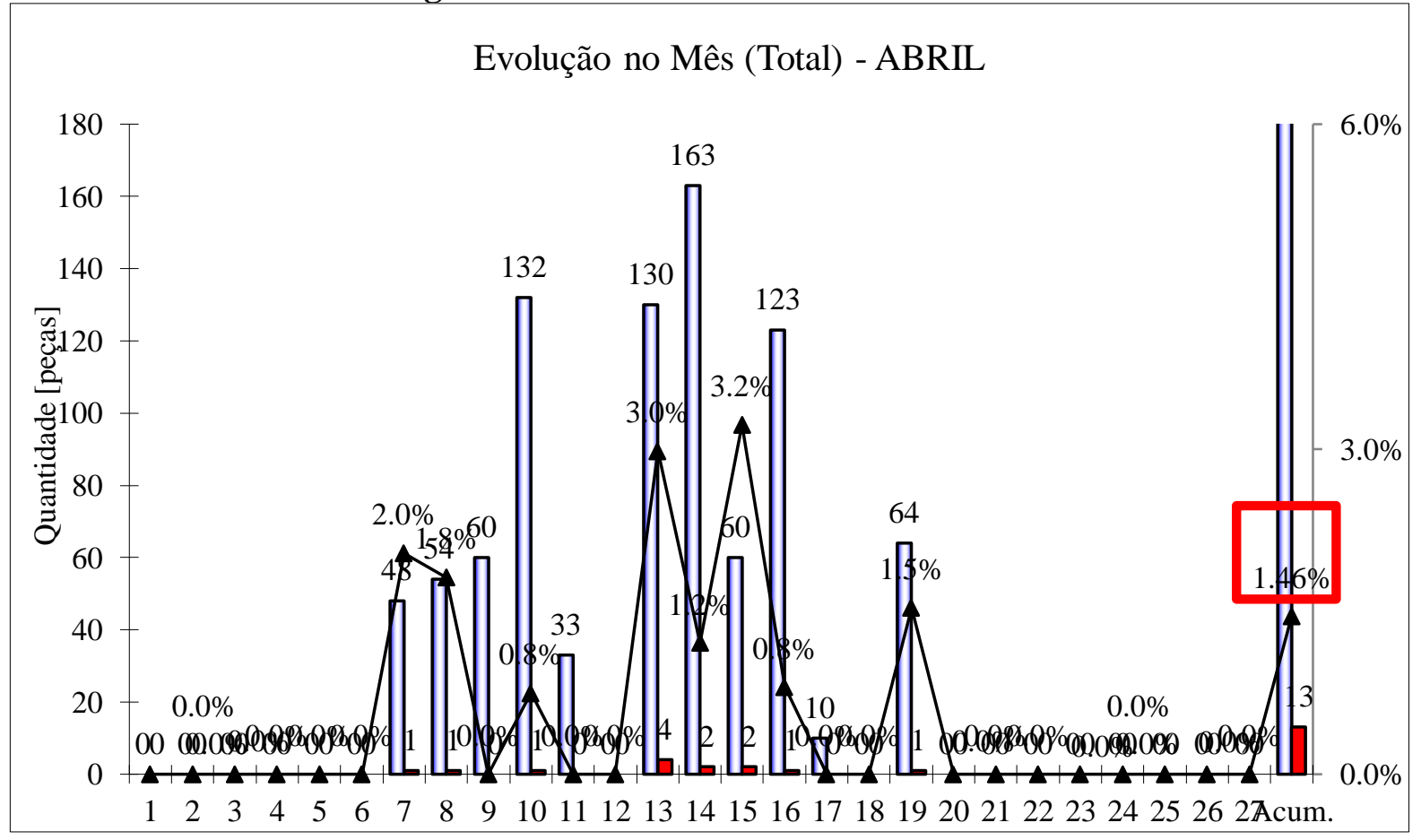

Fonte: Autores (2021)

\subsection{D4 - Identificar causa raiz}

Nessa etapa de identificação da causa-raiz, foi utilizada o brainstorming seguido do diagrama de Ishikawa, tendo como efeito peças com dificuldade de desempeno, conforme pode ser visto na Figura 6. 
Citação (APA): Soligo, L. P. \& Nunes, D. M. (2021). Aplicação da metodologia das 8 disciplinas para redução de uma não conformidade em uma empresa do setor automotivo. Brazilian Journal of Production Engineering, 7(5), 312-324.

Figura 6. Diagrama de causa e efeito no processo de desempeno.

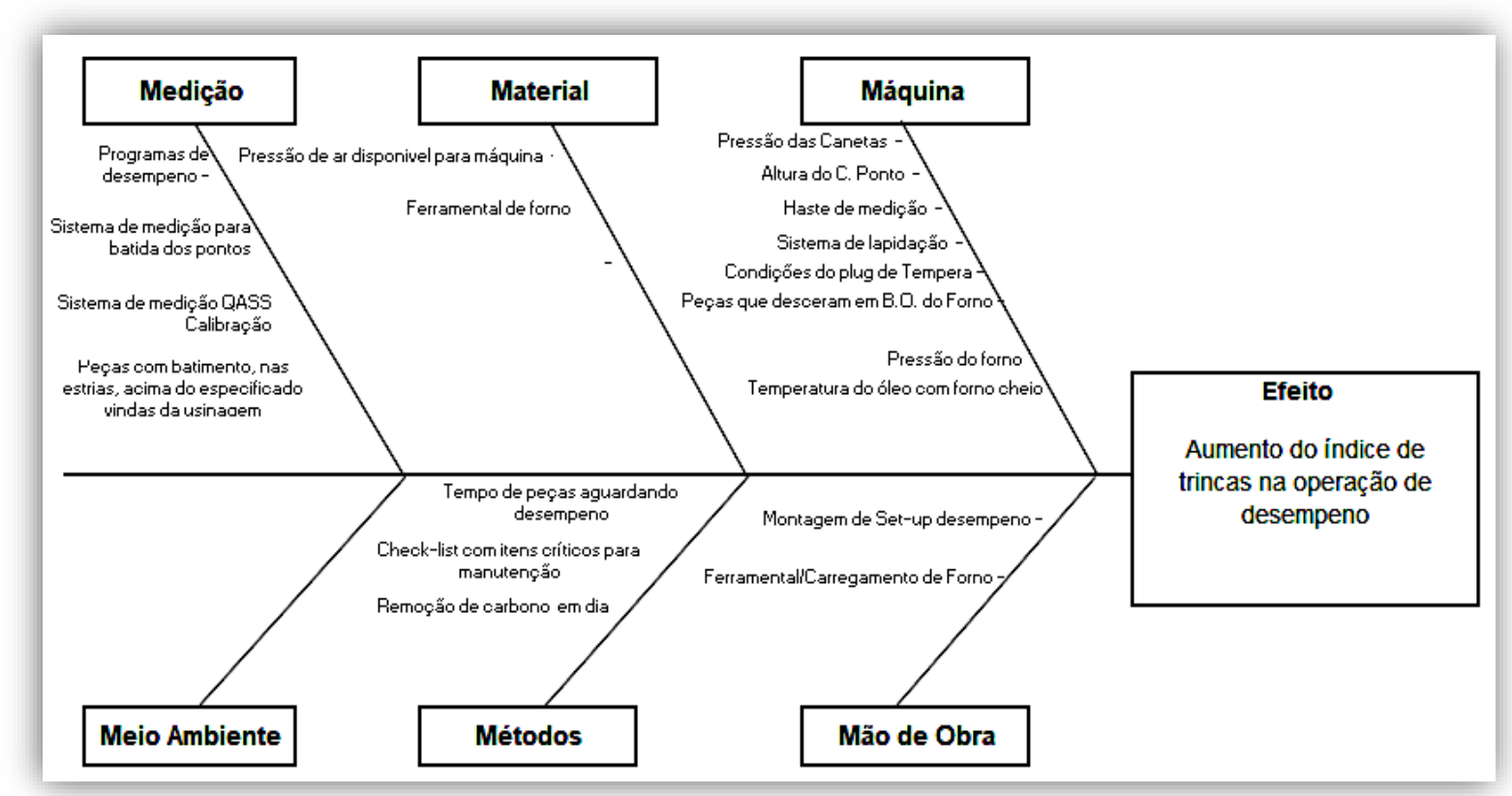

Fonte: Autores (2021)

Com o diagrama foi possível visualizar às causas potenciais e às oportunidades de melhoria para a minimização de ocorrências no problema no desempeno dos eixos. Dessa forma, a equipe multifuncional concluiu que as causas parâmetros do forno, tempo aguardando desempeno e forma de carregamento foram apontadas como possíveis causas de origem da falha.

Através da utilização de uma lista de verificação para os parâmetros do forno, conforme a Figura 7, durante os meses de dezembro/20 a abril/21, não foram identificadas alterações no forno, nas operações de têmpera e cementação. Concluindo-se que a causa parâmetros de forno não tem possibilidade de ser a causa raiz.

Figura 7. Folha de verificação para o forno. Check list

\begin{tabular}{|c|c|c|c|}
\hline Checagem FC\#10 & OK & NOK & Observações \\
\hline \multicolumn{4}{|l|}{ 1. Checar temperatura no gráfico e no painel de todas as zonas } \\
\hline \multicolumn{4}{|l|}{ 2. Checar temperatura no gráfico e no painel do B.O } \\
\hline \multicolumn{4}{|l|}{$\begin{array}{l}\text { 3- Verificar balanceamento entre as correntes de todas as zonas } \\
\text { e valores de offset corrigidos }\end{array}$} \\
\hline \multicolumn{4}{|l|}{ 4-Checagem da temperatura de segurança $\mathrm{BO}$ (max $200 . \mathrm{C}$ ] } \\
\hline \multicolumn{4}{|l|}{$\begin{array}{l}\text { 5- Aferir com tacômetro a receita de agitação do B.O e verificar } \\
\text { se está de acordo com a Instrução IT-T-070 }\end{array}$} \\
\hline \multicolumn{4}{|l|}{ 6. Verificar sentido da rotação do agitador BO } \\
\hline \multicolumn{4}{|l|}{ 7-Verificar estabilidade do \% de carbono na WS } \\
\hline \multicolumn{4}{|l|}{ 8- Verificar resultado das chapinhas } \\
\hline \multicolumn{4}{|l|}{ 9-Verificar resultado dos pinos } \\
\hline \multicolumn{4}{|l|}{ 10 - Verificar uniformidade do carregamento no forno } \\
\hline \multicolumn{4}{|l|}{ 11- Verificar os tempos de pista } \\
\hline \multicolumn{4}{|l|}{ 12- Checagem diário de bordo (DP) } \\
\hline \multicolumn{4}{|l|}{ 13-Verificar funcionamento do filtro de óleo } \\
\hline \multicolumn{4}{|l|}{$\begin{array}{l}14 \text { - Verificar qualidade do ferramental utilizado no carregamento, } \\
\text { posigẫo do "V" }\end{array}$} \\
\hline \multicolumn{4}{|l|}{15 - Verificar pressẫo do forno } \\
\hline \multicolumn{4}{|l|}{$\begin{array}{l}\text { 16- Verificar fluwo de atmosfera do forno - abertura dos escapes } \\
\text { Padrâo: Fluno para a frente do forno }\end{array}$} \\
\hline $\begin{array}{l}17 \text { - Verificar a rastreabilidade do aço que está sendo utilizado no } \\
\text { verde [anote o número] }\end{array}$ & & & \\
\hline
\end{tabular}

Fonte: Autores (2021) 
Citação (APA): Soligo, L. P. \& Nunes, D. M. (2021). Aplicação da metodologia das 8 disciplinas para redução de uma não conformidade em uma empresa do setor automotivo. Brazilian Journal of Production Engineering, 7(5), 312-324.

Foi observado o tempo de armazenamento do eixo após a operação da têmpera até a operação de desempeno, neste período, e foi visto que a operação de desempeno estava trabalhando em fluxo com o forno e, uma vez que, o tempo crítico de armazenamento estabelecido pelo controle de qualidade era de 2 dias, concluiu-se que tempo aguardando desempeno não foi a causa raiz para o surgimento de trincas.

A causa ferramental de carregamento das peças no forno, não representou potencial para não conformidades dos eixos, uma vez que, os eixos são carregados na vertical em uma gaiola de transporte o que torna adequada para a operação, pois suspende o eixo e faz com que ele não apoie na base inferior do ferramental, impossibilitando a inclinação e o empeno das peças.

Com as possíveis causas descritas anteriormente descartadas, decidiu-se olhar para as etapas anteriores, focando na área de usinagem, chamada de "Área verde" dentro da empresa. Neste setor, o forjado é torneado, cortado e furado. A Figura 8 descreve as etapas do processo nesta área.

Figura 8. Mapeamento do processo de usinagem.

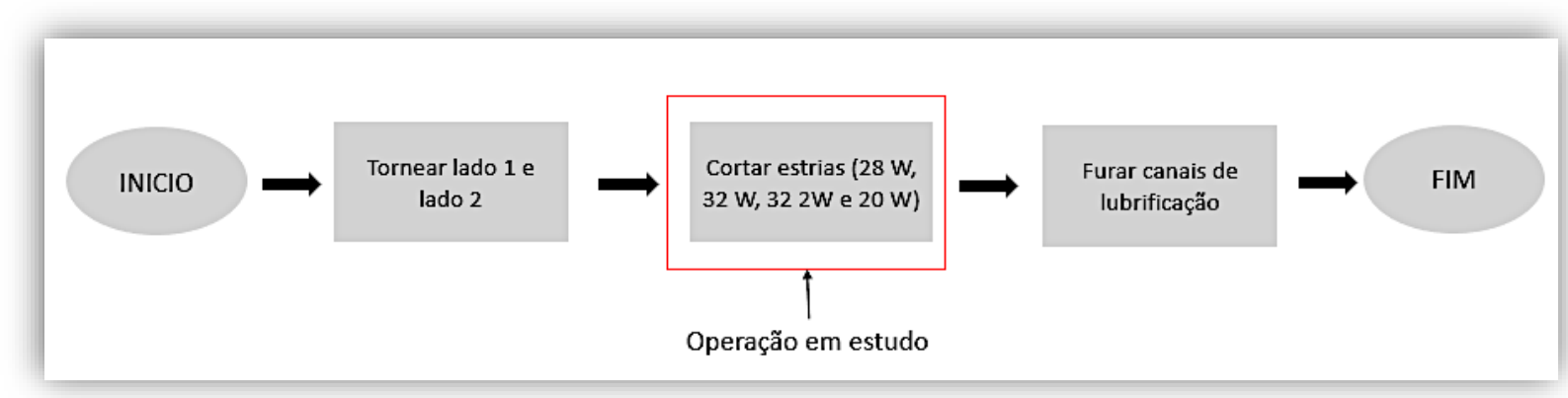

Fonte: Autores (2021)

Para se ter ideia das condições em que as peças estavam sendo enviadas para o tratamento térmico, decidiu-se analisar um lote de 30 peças advindas da "Área verde" para serem medidos as batidas nas 2 estrias ( $32 \mathrm{~W}$ e $32 \mathrm{2W}$ ). O desvio de batimento representa a oscilação da posição de um elemento, considerado ao girar a peça em uma rotação em torno de um eixo de referência, sem que haja deslocamento axial. Para realizar a leitura, foi necessário o auxílio de um entre pontos horizontal e um relógio indicador.

As Figuras 9 e 10, respectivamente, representam a capabilidade do processo de corte das estrias. Em ambos os casos, observou-se que a média amostral estava acima do limite superior especificado, uma vez que, os dados se posicionaram significativamente fora do limite de especificação da batida na operação. 
Figura 9. Capabilidade no processo de corte estria $32 \mathrm{~W}$

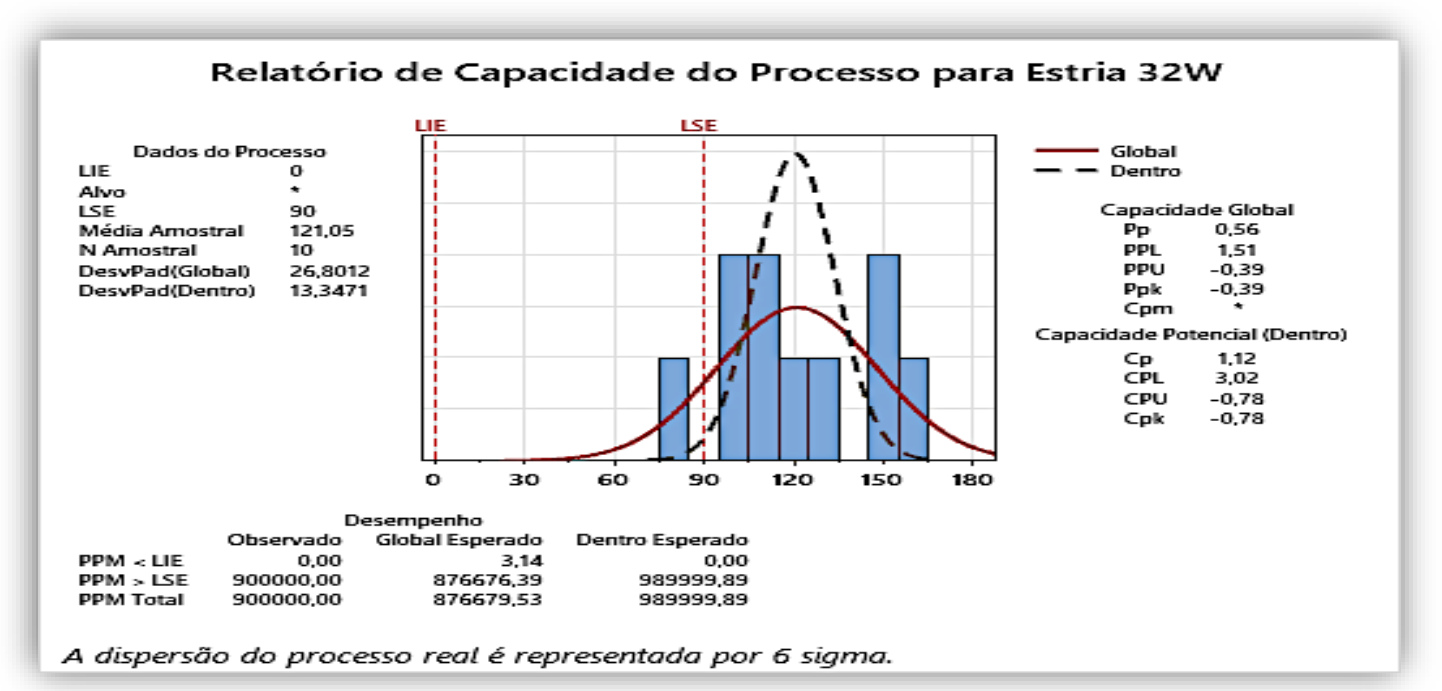

Fonte: Autores (2021)

Figura 10: Capabilidade no processo de corte na estria $322 \mathrm{~W}$

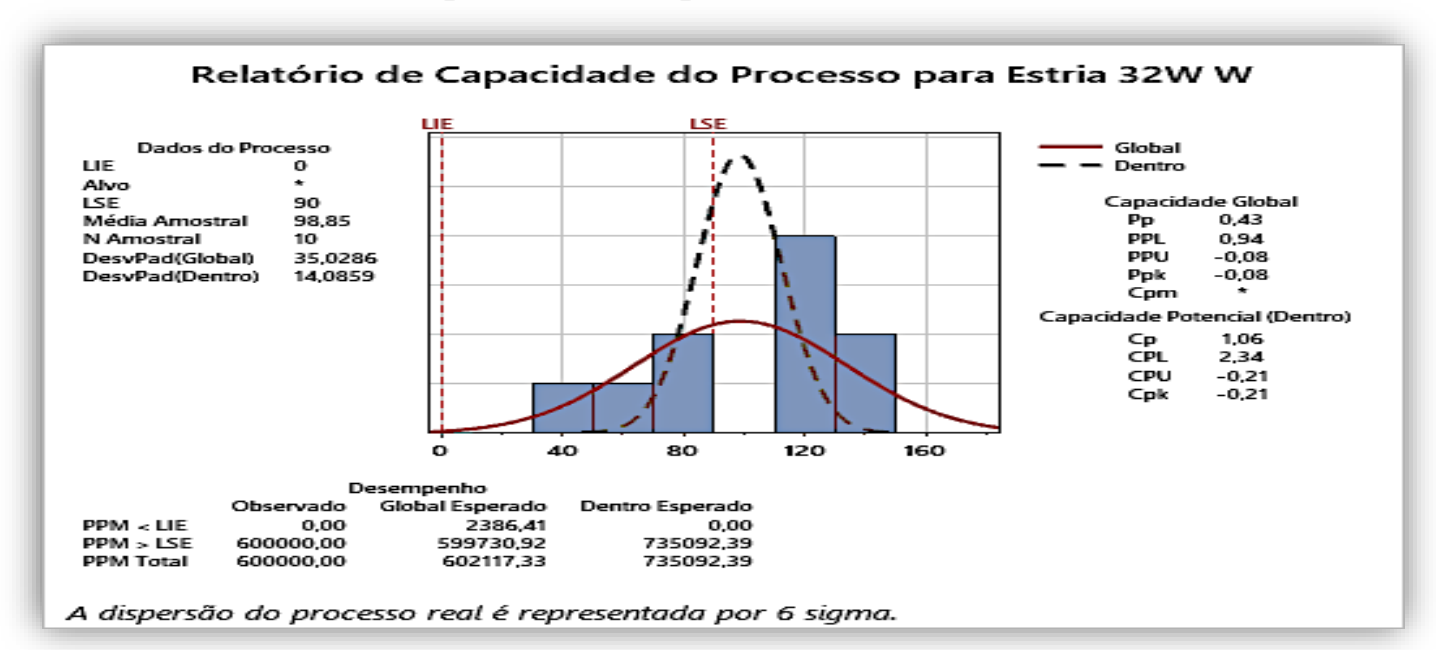

Fonte: Autores (2021)

Pode-se verificar, ainda nas Figuras 9 e 10, que os valores de Cpk foram negativos, isto quer dizer que, a máquina não era capaz de produzir peças dentro do especificado no processo, ou seja, se Cpk apresentar sinal negativo, há desvio da média fora do campo de tolerância e quanto maior for o módulo de Cpk negativo maior o deslocamento da média em relação ao limite de tolerância considerado. Esses resultados permitiram definir que a operação usinagem-corte era o ponto critico no aumento do índice de trincas.

Com a operação critica levantada, implementou-se um Programa de Aceleração de Melhoria Contínua (PAMC) na máquina em questão e identificou-se uma inadequação de projeto nos pontos de fixação da mesma que causava um desalinhamento entre os pontos, ocasionando um corte desigual das estrias e, consequentemente, as batidas fora de sua especificação.

\subsection{D5 - Identificar ação corretiva}

Com a causa raiz identificada, reuniram-se equipe de projeto e da manutenção para agirem corretivamente no desempenho da máquina. Durante a reunião, definiu-se a retirada de um 
sobremetal de $7 \mathrm{~mm}$ de espessura da lateral do dispositivo para centralizar o ponto superior ao ponto inferior da peça. A análise da causa raiz também foi feita através da ferramenta $5 \mathrm{~W} 2 \mathrm{H}$, conforme a Tabela 1, identificando qual o defeito no produto e no processo a ser atacado.

Tabela 1. Plano de ação $-5 \mathrm{~W} 2 \mathrm{H}$.

\begin{tabular}{|c|c|c|c|c|c|}
\hline What? & How? & Who? & When? & Where? & How Much? \\
\hline \multirow{2}{\text{Melhorar}}{$\begin{array}{c}\text { capacidade da } \\
\text { máquina de } \\
\text { fresadora }\end{array}$} & $\begin{array}{c}\text { Retrabalhar dispositivo } \\
\text { de fixação da máquina }\end{array}$ & $\begin{array}{c}\text { Equipe de } \\
\text { manutenção }\end{array}$ & 1 dia & $\begin{array}{c}\text { Serralheria da } \\
\text { fábrica }\end{array}$ & - \\
\cline { 2 - 6 } & retrabalhado na máquina & $\begin{array}{c}\text { Equipe de } \\
\text { manutenção }\end{array}$ & 1 dia & Célula em estudo & - \\
\hline
\end{tabular}

Fonte: Autores (2021)

\subsection{D6 - Implementar ação corretiva}

Com o plano de ação traçado, foram feitas as ações corretivas para melhoria do processo. Foi necessário acompanhar o processo de fabricação e atualizar a máquina com o dispositivo retrabalhado, através do Programa de Aceleração de Melhoria Contínua (PAMC). Após a implementação das ações, observou-se, através de um novo estudo de capabilidade, que o processo passou a ser capaz e estável, como indicam as Figuras 11 e 12.

Figura 11. Capabilidade no processo de corte estria $32 \mathrm{~W}$

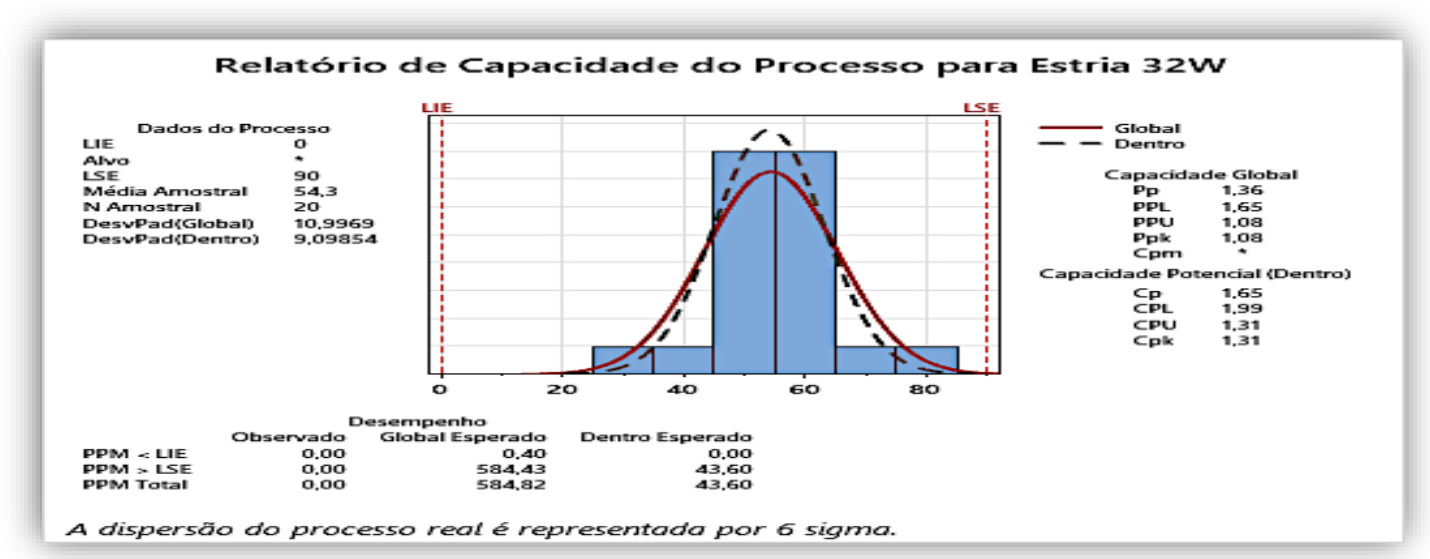

Fonte: Autores (2021)

Figura 12. Capabilidade no processo de corte na estria $322 \mathrm{~W}$

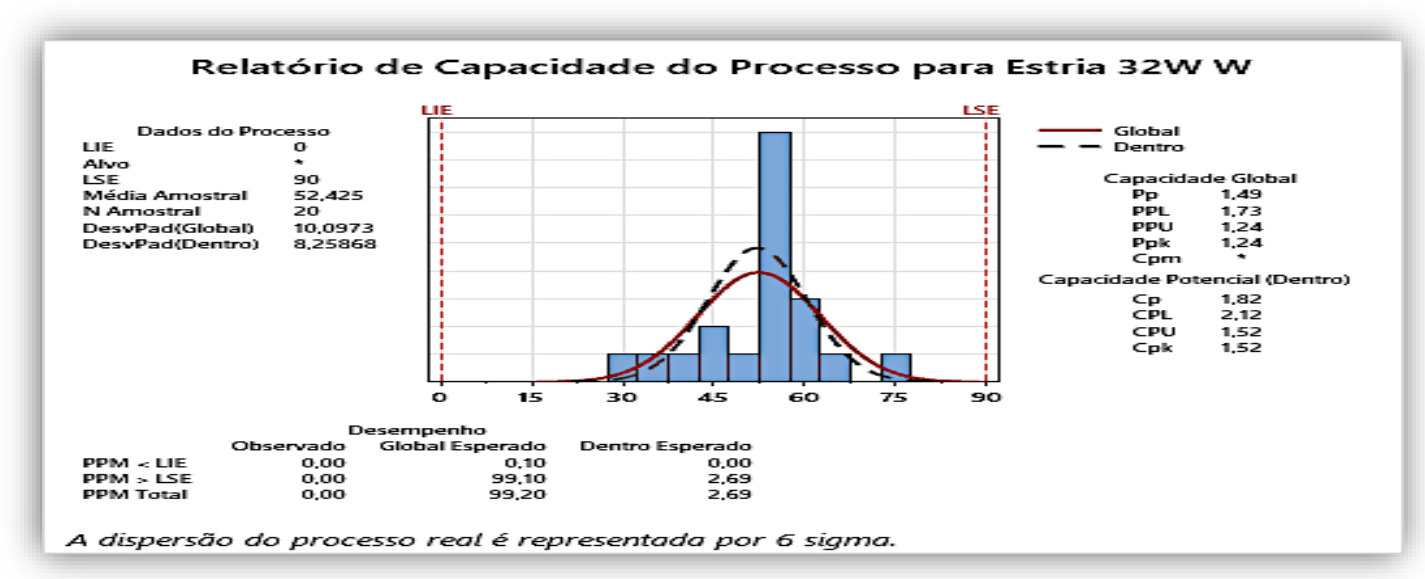


Fonte: Autores (2021)

\subsection{D7 - Plano de controle}

Com a implementação do novo ponto na máquina, algumas medidas foram tomadas para fiscalizar e garantir a conformidade dos próximos lotes a ser produzidos. A implementação de um controle da batida do ponto durante o setup da máquina e a inclusão de uma auditoria das peças da "Área verde" no checklist de prevenção de trincas possibilitou que não houvesse liberação de peças sem inspeção e, consequentemente, uma redução do índice de trincas nos eixos de transmissão, conforme a Figura 13.

Figura 13. Índice de trincas

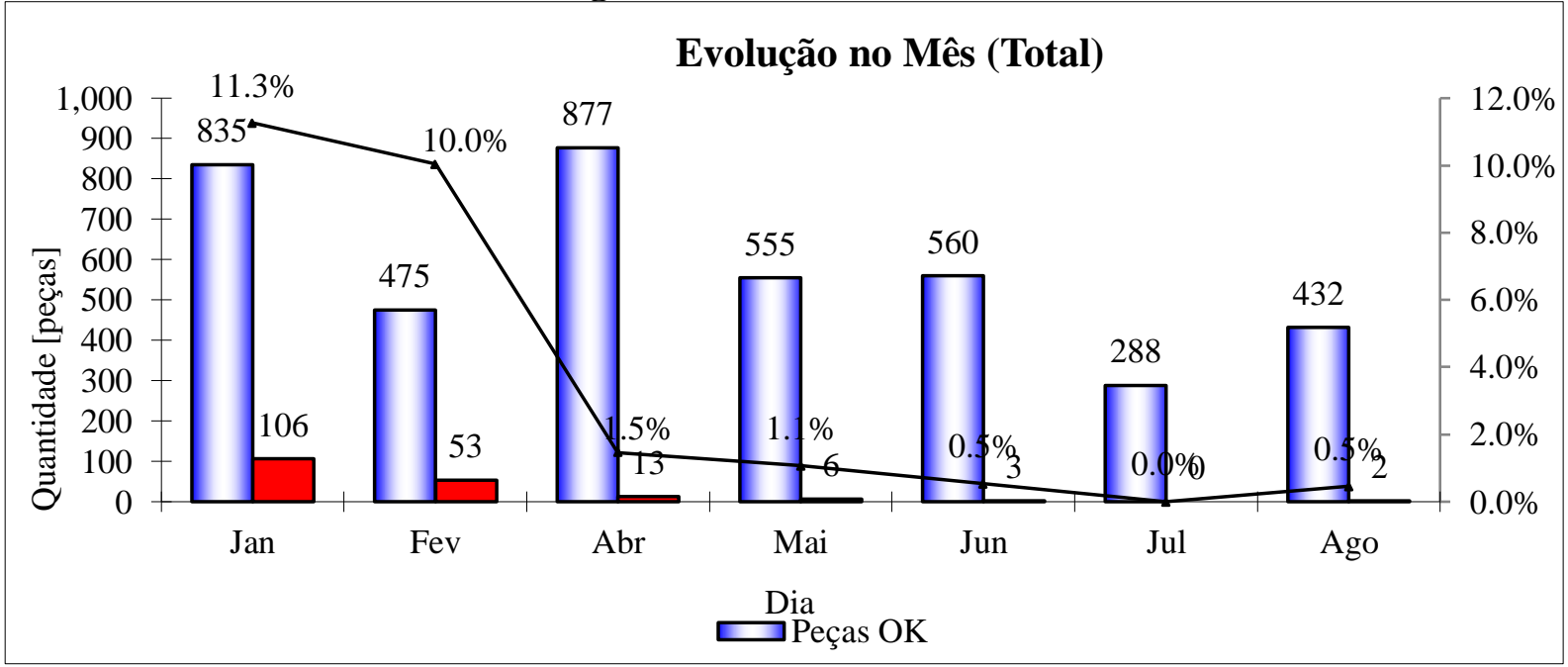

Fonte: Autores (2021)

Percebeu-se que foi possível a redução do índice de trincas para os meses de maio a agosto de 2021 após a implementação da ação corretiva e o acompanhamento do processo pelo Programa de Aceleração de Melhoria Contínua (PAMC), de 11,3\% para 0,5\%. Isso permitiu o atendimento da meta estabelecida de não conformidades de $1 \%$, resultando numa redução significativa de $95,58 \%$ no índice de trincas dos eixos de transmissão com a aplicação da metodologia 8D.

\subsection{D8 - Parabenizar a equipe}

Após a comprovação da eficácia da ação corretiva o responsável por liderar a equipe durante as etapas do método $8 \mathrm{D}$, marcou a última reunião com a finalidade de parabenizar a equipe por atingir o objetivo de encontrar uma solução eficaz e eficiente para a não conformidade detectada.

\section{CONCLUSÃO}

O trabalho teve como intuito apresentar um cenário em que o alto índice de não conformidades vinha causando um grande impacto para a organização e demonstrar a eficácia da aplicação da metodologia 8D para a resolução deste problema.

Com a aplicação das 8 disciplinas e de ferramentas estudadas no curso de Engenharia de Produção, foi possível evidenciar o problema e apresentar os passos realizados para atingir o objetivo proposto no início do projeto, que foi a redução do índice de trincas nos eixos de transmissão. 
A partir da implementação das ações corretivas desenvolvidas durante este estudo, observouse uma melhoria significativa na operação corte-usinagem, passando a ser um processo capaz e estável como indicam os CPKs de 1,31 e 1,52. Consequentemente, ocorreu uma redução de, aproximadamente, $96 \%$ das trincas nos eixos de transmissão, o que corresponde a redução de $11,3 \%$ para $0,5 \%$, atingindo a marca de $1 \%$ pré-estabelecida como objetivo.

Por tanto, com os resultados obtidos, conclui-se que o objetivo do trabalho foi atingido com êxito e sugere-se o uso da metodologia 8D na análise de outros problemas, podendo assim, explorar outras ferramentas da qualidade.

\section{REFERÊNCIAS}

Vargas, D. L. (2017) Resolução de problemas utilizando a metodologia 8D: estudo de caso de uma indústria do setor sucroalcooleiro. In: Simpósio de Engenharia de Produção de Sergipe, São Cristóvão, $\quad$ SE, $\quad$ Brasil. $\quad$ Recuperado de https://ri.ufs.br/bitstream/riufs/7672/2/ResolucaoProblemasMetodologia8D.pdf

Cintra, A. L. (2015). Utilização da metodologia 8D para resolução de problemas: estudo de caso de fornecedores de uma multinacional da linha branca (Trabalho de Conclusão de Curso) Escola de Engenharia de São Carlos, São Carlos, SP, Brasil. Recuperado de file:///C:/Users/Samsung/Downloads/Cintra_Ana_Livia_Barbosa_tcc\%20(1).pdf

Chies, S., de. (2019). A aplicação da ferramenta $8 d$ para a resolução de problemas de qualidade no cliente. CIPPUS. Canoas, 7(2). Recuperado de file:///C:/Users/Samsung/Downloads/6306-20155-1-PB\%20(1).pdf

Montgomery, D. C. (Ed). (2017). Introdução ao Controle Estatístico de Qualidade. Rio de Janeiro: Editora LTC.

Almeida, J. F., Matias, L. R., Braga, W. L. M., \& Junior, F. R. L. (2014). Aplicação da metodologia MASP ao processo de alteração técnica de produtos em uma indústria de médio porte. Anais do XXXVI Encontro Nacional de Engenharia de Produção, Curitiba, PR, Brasil. Recuperado de http://www.abepro.org.br/biblioteca/enegep2014 TN STO 196112 25492.pdf

Martins, G. H., de. (2016). Aplicabilidade da metodologia de análise de soluções de problemas MASP através do ciclo PDCA no Setor de Embalagens: Estudo de caso na "Indústria de Embalagens" no Brasil. Journal of Lean Systems, 1(4), 02-22 Recuperado de https://docplayer.com.br/82755499-Aplicacao-do-ciclo-pdca-para-solucoes-de-problemasmasp-no-setor-de-embalagem-estudo-de-caso-na-industria-de-embalagens-resumo.html

Seleme, R. \& Stadler, H. (Ed). (2012). Controle da qualidade: as ferramentas essenciais. Curitiba: InterSaberes.

Abdulmalek, F. A. \& Rajgopal, J. (2007). Analyzing the benefits of lean manufacturing and value stream mapping via simulation: A process sector case study. International Journal of Production Economics, 107(1), 223-236. https://doi.org/10.1016/j.ijpe.2006.09.009

Sodré, E. (2020, Março 18). Por coronavírus, montadoras dão férias coletivas e já demitem no Brasil. Folha de São Paulo. Recuperado de https://www1.folha.uol.com.br/mercado/2020/03/por-coronavirus-montadoras-dao-feriascoletivas-e-ate-demitem-no-brasil.shtml

Cunha, J. (2019). Indústria automotiva projeta alta de 11,4\% nas vendas em 2019. Folha de São Paulo. Recuperado de https://www1.folha.uol.com.br/mercado/2019/01/industria-automotivaprojeta-alta-de-114-nas-vendas-em-2019.shtml

Romani, A. (2019). IBGE: Setor automotivo tem maior crescimento em 11 anos. Veja. Recuperado de https://veja.abril.com.br/economia/ibge-setor-automotivo-tem-maiorcrescimento-em-11-anos/ 